\title{
Early changes in peritumorous oedema and contralateral white matter after dexamethasone: a study using proton magnetic resonance spectroscopy
}

Paul Chumas, Barrie Condon, David Oluoch-Olunya, Stuart Griffiths, Donald Hadley, Graham Teasdale

\begin{abstract}
Aims-To study the mechanism of action of steroids in patients with peritumorous oedema.

Methods-To investigate early cerebral metabolic changes proton magnetic resonance spectroscopy ('H-MRS) was used before and 11 to 14 hours after treatment with dexamethasone $(12 \mathrm{mg}$ oral loading and $4 \mathrm{mg}$ four times daily maintenance). Nine patients (two men, seven women, mean age 54) with pronounced oedema associated with various intracranial tumours (two astrocytomas, three meningiomas, two glioblastoma, and two metastases) were examined using MRI and MRS. SE1500/135 volume selected MRS (mean volume $21 \mathrm{ml}$ ) were performed on an oedematous region and a contralateral region. All spectra were acquired with and without water suppression. Metabo-
\end{abstract} lite peak area ratios were determined.

Results-Regions of oedema had significantly $(P<0.01)$ higher unsuppressed water than the contralateral regions, as expected. There was no change at this early time point after dexamethasone. The ratio of the area of choline containing compounds to that creatine and phosphocreatine compounds was determined after which the serial ratios of these before and after were calculated (a serial ratio of 1.0 would indicate no change in the choline to creatine ratios after steroid administration). The mean serial ratios for the area of oedema were 1.02 (SEM 0.08) and 1.10 $(0.08)$ for the contralateral volume of interest, indicating no significant changes. However, significant changes $(P$ $<0.02$ ) were found in the $\mathrm{N}$-acetyl-aspartate (NAA)/choline serial ratios $(0.86$ $(0.06)$ in the area of oedema, $1.20(0 \cdot 10)$ in contralateral brain) and the NAA/creatine serial ratios $(0.86(0.08)$ for the oedema, $1.25(0 \cdot 11)$ in contralateral brain).

Conclusions-Such rapid changes may be explained either by relatively large alterations in the relaxation characteristics of NAA or, more controversially, by actual changes in the amounts of NAA. It is proposed that steroids act primarily by causing early metabolic changes that are later expressed in improvements in intracranial volume relations.

$(\mathcal{F}$ Neurol Neurosurg Psychiatry 1997;62:590-595)
Keywords: brain; dexamethasone; peritumorous oedema; spectroscopy; metabolism

Steroids are routinely employed in the treatment of patients with tumours of the CNS yet their mode of action remains obscure. In particular, the rapid and dramatic clinical improvement seen in some patients is difficult to explain on the basis of changes in bloodbrain barrier permeability, ${ }^{12}$ blood flow or volume, ${ }^{3-5}$ decrease in CSF production, ${ }^{16}$ or resolution of peritumorous oedema. ${ }^{7}$ We have utilised proton magnetic resonance spectroscopy ( $\left.{ }^{1} \mathrm{H}-\mathrm{MRS}\right)$ to study peritumorous oedema before and after treatment with dexamethasone to examine possible early metabolic changes.

\section{Materials and methods}

Nine patients (two men, seven women, mean age 54) with primary space occupying brain tumours were examined using a $1.5 \mathrm{~T}$ Siemens Magnetom with a standard quadrature trans$\mathrm{mit} /$ receive head coil. Collimated light localisers were used to serially reposition the patient's head with respect to the coil and magnet. SE1500/135 (256 averages) volume selected MRS was performed on the oedematous region and a contralateral region. All spectra were obtained with water suppression (256 averages) and without it (one average). The chemical shift selective saturation CHESS sequence was used for water suppression. Global and then local shimming were used to bring the unsuppressed water linewidth (full width at half maximum) in the selected volume of interest (VOI) to within $10 \mathrm{~Hz}$.

A standard T2 weighted MRI sequence (SE2200/80, $192 \times 256,20 \times 5 \mathrm{~mm}$ slices in the axial orientation) was acquired both before and after treatment to ensure that no macroscopic changes in brain water had occurred over this short time frame. In addition "scout" sets of sagittal and coronal images were acquired using an SE400/15 (128 × 256, 10 $\times 10 \mathrm{~mm}$ slices) to guide positioning of the VOIs in conjunction with the T2 weighted axial image (fig 1). These were placed within the oedema but excluding the tumour itself. To optimise signal to noise ratios VOIs were chosen to encompass as much oedematous white matter as possible, but not to be near the inner table of the skull to avoid line broadening and lipid contamination of the spectra by marrow and scalp. A second VOI was placed 
Figure 1 Images showing typical positioning of VOI over oedema: (A) axial,

(B) sagittal, (C) coronal.

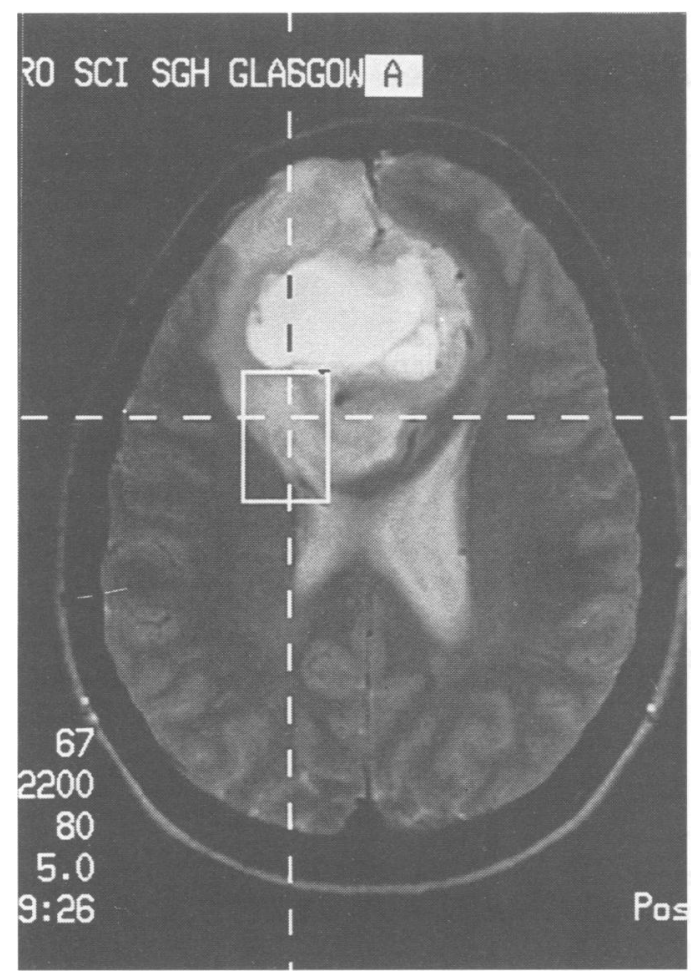

A

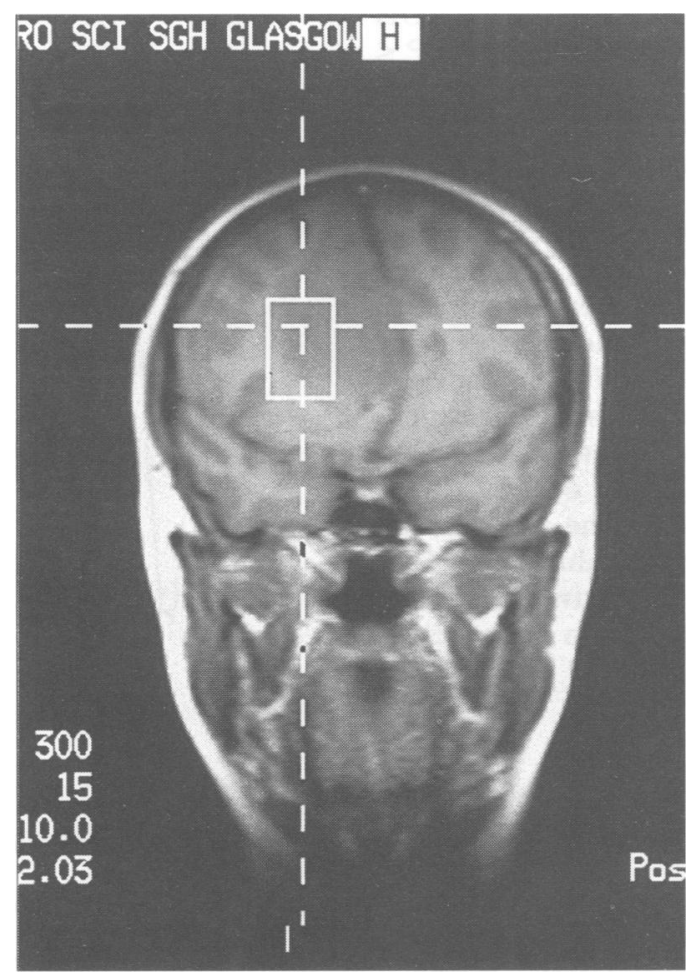

C

over the contralateral brain region and a spectrum acquired. Figure 2 shows a T2 weighted positioning image. Hard copy films of the "scout" sets and VOI placements were obtained and these were used as references to guide positioning of the VOI in the post treatment acquisitions to obtain as close a spatial correspondence as possible.

After acquisition a fast Fourier transform was applied to convert the time domain signals into frequency domain spectra. No filtering was applied and the only baseline manipula-

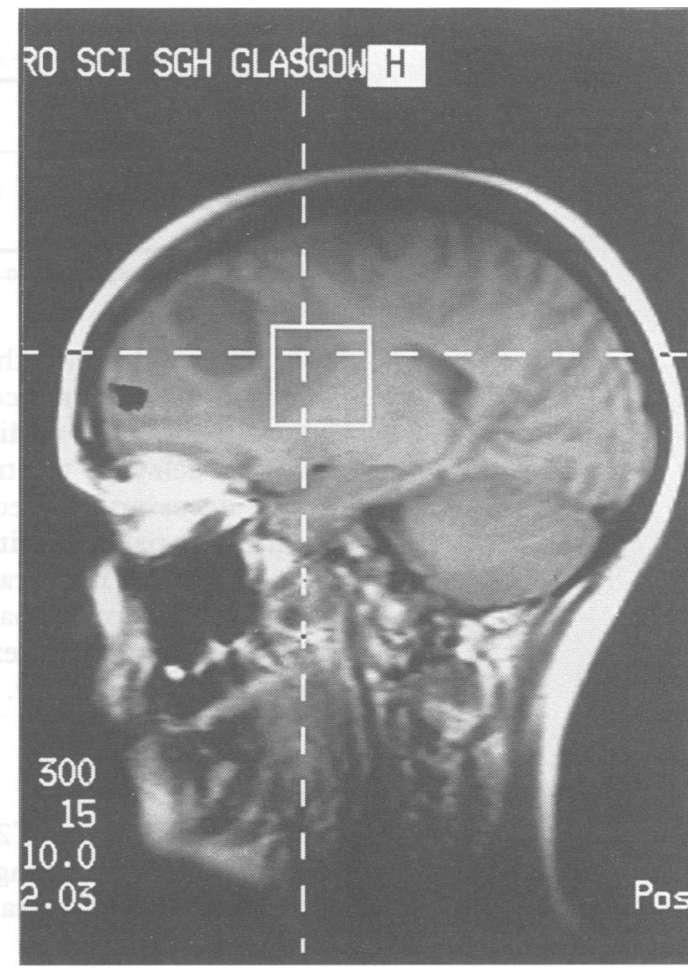

B

tion used was the interactive phase correction of the frequency data to make the baseline as linear as possible over the frequency range of the metabolites of interest. There is always some degree of subjectivity inherent in choosing integration limits for peak area calculations so to avoid introducing between observer errors all peak area calculations were performed by one observer (BC).

Ethical approval was obtained for this study and each patient signed a consent form before participating. Recruitment of patients was diffi-

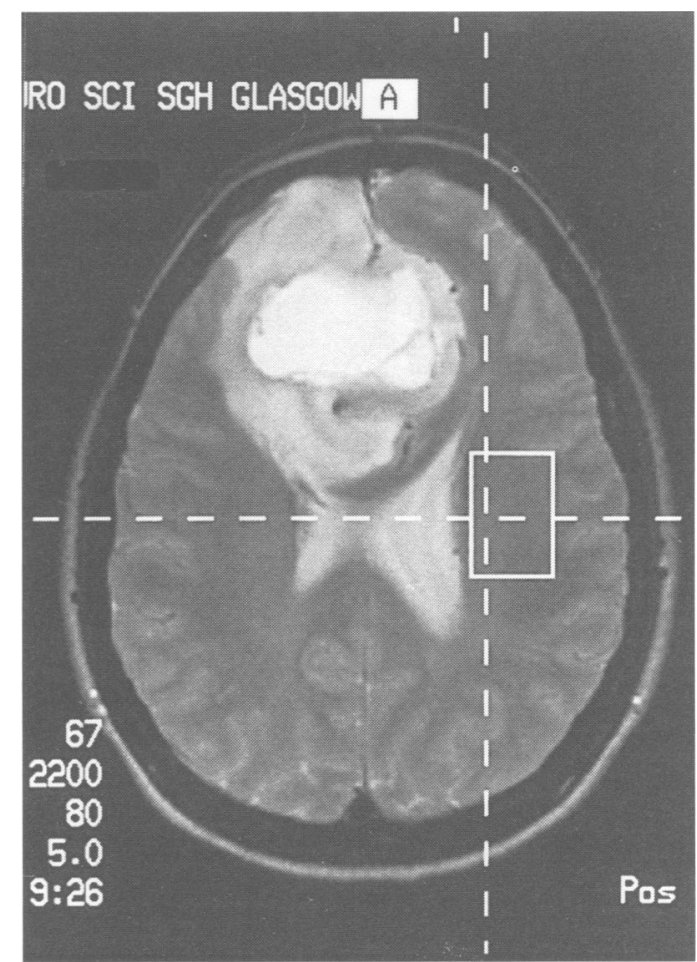

Figure $2 \quad T 2$ axial slice showing typical positioning of contralateral VOI. 
Mean (SEM) serial metabolite ratio changes before and after dexamethasone

\begin{tabular}{llll}
\hline Serial ratios & Oedema & $\begin{array}{l}\text { Contralateral } \\
\text { side }\end{array}$ & Pvalue \\
\hline NAA/Cho & $0.86(0.16)$ & $1.20(0.10)$ & $<0.02$ \\
NAA/Cr & $0.86(0.08)$ & $1.25(0.11)$ & $<0.02$ \\
Cho/Cr & $1.02(0.08)$ & $1.10(0.08)$ & - \\
\hline
\end{tabular}

Mean $1 \cdot 00$ would represent no change.

cult due to the fact that referring physicians had often commenced steroid treatment before transfer. In addition, ethical considerations in delaying treatment even for the few hours necessary to secure an MR time slot meant that patients with florid symptoms and signs of raised intracranial pressure were not studied. None of the patients showed dramatic improvement after dexamethasone over the time scale of the study.

\section{Results}

Comparison of the T2 weighted images disclosed no visible changes in oedema contrast or extent after dexamethasone treatment. Similarly there were no significant serial changes in the unsuppressed water peaks either in the oedematous or normal sides, which support previous findings. ${ }^{7}$ The VOIs over oedema had significantly higher $(\mathrm{P}<$ 0.01 ) unsuppressed water peak areas than those over the contralateral side, as expected.

The area ratios calculated were $\mathrm{N}$-acetyl aspartate (NAA)/choline (Cho), NAA/creatine + phosphocreatine $(\mathrm{Cr})$ and $\mathrm{Cho} / \mathrm{Cr}$, where Cho refers to the peak reflecting choline containing compounds and $\mathrm{Cr}$ refers to the peak reflecting creatine and phosphocreatine compounds. As expected the VOI over oedematous brain before dexamethasone treatment showed some reduction in the NAA/Cho ratios with a mean (SD) ratio of $1.52(0.89)$ compared with $1.84(0.24)$ in the contralateral VOI. For NAA/Cr ratios the values were $1 \cdot 78$ $(0.36)$ and $1.90(0.28)$ respectively. Choline to creatine ratios differed more in the oedematous VOI with a mean of $1.79(1.45)$ com-

Figure 3 Mean (SEM) serial peak area ratios for oedema and contralateral side.

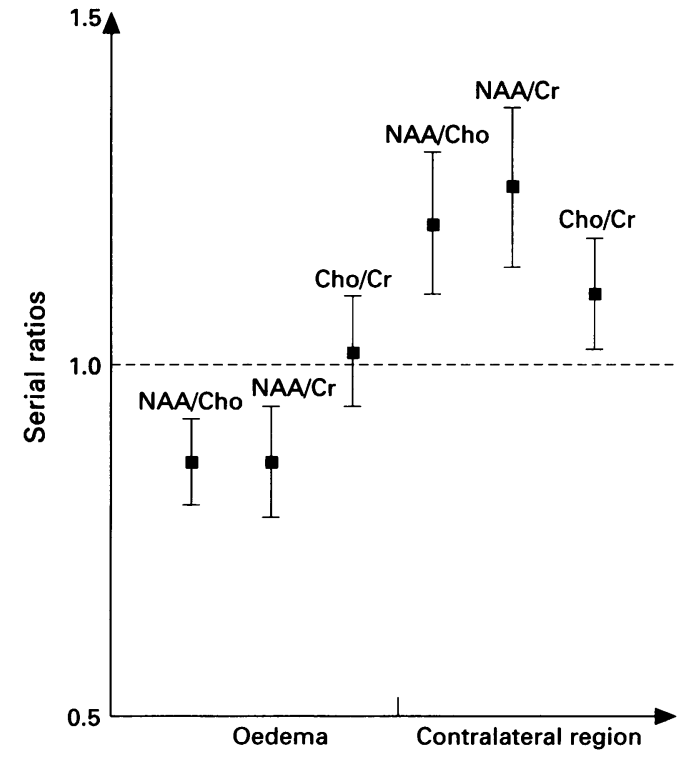

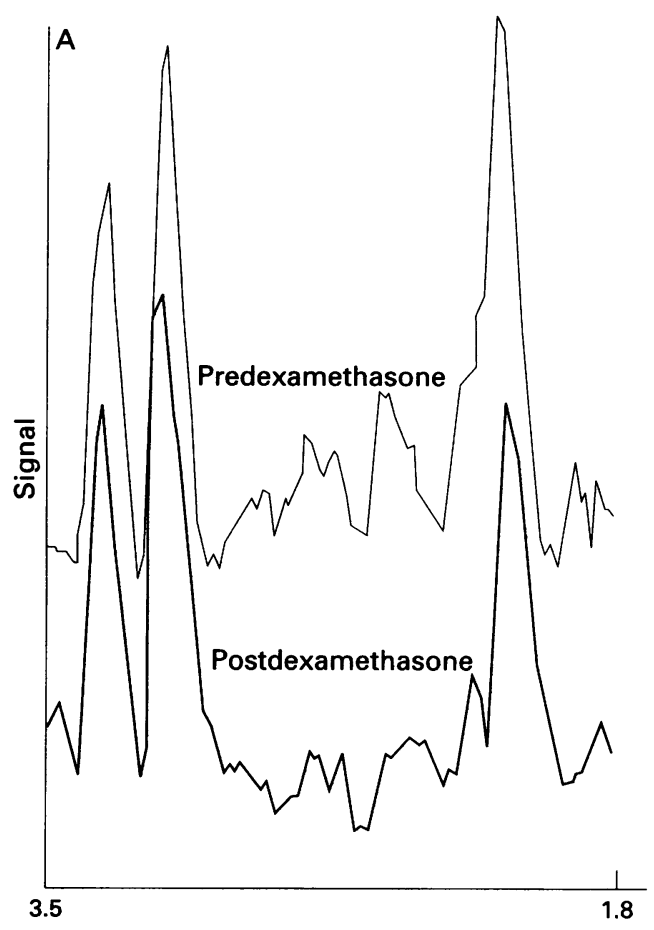

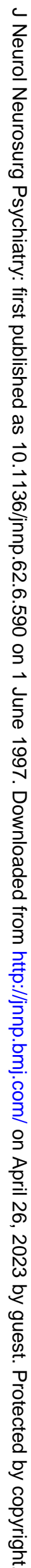


gives the actual mean values obtained from the nine patients. Figure 3 displays these graphically. A $t$ test was used to determine the statistical differences between serial ratio changes in the oedematous side and serial ratio changes in the contralateral side. Combined SDs were used in these calculations as the sample size was small $(<30)$.

There were pronounced differences in the way the metabolite ratios change. Whereas choline/creatine serial ratios did not change significantly, serial ratios involving NAA showed a significant divergence between the oedema and contralateral VOIs, with NAA peak areas apparently decreasing by an average of $14 \%$ on the oedematous side and increasing by an average of $22 \%$ on the contralateral side (see discussion).

Figure 4 (A and B) shows serial spectra over oedematous and contralateral regions. Small relative decreases in the NAA in the oedematous region and relative increases in the contralateral region are observable.

Negative peaks at the chemical shift position corresponding to lactate were found in all patients in the oedema spectra, and in one instance in the contralateral spectra. These peak areas were generally small compared with the metabolite peak areas and showed no evidence of change after dexamethasone.

\section{Discussion}

Steroids have been used in the treatment of brain tumours since the early 1950 s when Ingraham et al noted benefit from their use in patients with craniopharyngioma ${ }^{8}$ However, it was not until the report of Galicich et al in 1961 that the wider application of steroids for all CNS tumours was recognised. ${ }^{9}$ Over the past 30 years, numerous studies have been performed to attempt to elucidate the mechanisms of action but none have been able to explain the rapid clinical response. In the present study, significant metabolic changes were seen within 14 hours, both in the zone of oedema around the tumour and in the contralateral hemisphere. A finding all the more surprising considering the largely asymptomatic nature of many of the patients and the lack of obvious clinical change. We propose that steroids have a primary metabolic action-of which the changes in NAA seen in this study represent only a small part. Any changes in blood-brain barrier permeability and resolution of the oedema being secondary to the altered metabolic milieu. The time scale of these changes is in keeping with possible enzyme induction or inhibition.

PREVIOUS CONCEPTS OF THE ACTIONS OF STEROIDS IN PATIENTS WITH A BRAIN TUMOUR After treatment with steroids clinical improvement is usually seen within the first 24 hours. ${ }^{1011}$ Previous investigators have measured the intracranial pressure in patients with cerebral tumours before and after treatment with steroids and shown that although there is a rapid decrease in the frequency and amplitude of plateau waves, the baseline intracranial pressure remains increased for some days. ${ }^{312-14}$ Miller and Leech showed a favourable alteration of the volume-pressure curve within 24 hours after starting steroids, indicating a change in brain elasticity with a greater ability to compensate. ${ }^{14}$ It may be that this change relates to the decreased CSF production seen after dexamethasone. ${ }^{615}$ However, similar degrees of reduction in CSF production can be seen after treatment with acetazolamide ${ }^{1016}$ which does not benefit patients with brain tumours. Furthermore, the response to steroids is variable with no effect on CSF production after dexamethasone in rhesus monkeys. ${ }^{17}$

Other investigators have concentrated on changes in regional cerebral blood flow (rCBF) and regional cerebral blood volume (rCBV) but again very variable results have been obtained. Reulen et al showed an increase in $\mathrm{rCBF}$ after five to seven days of treatment with dexamethasone ${ }^{5}$ whereas Leenders et al reported a decrease in $\mathrm{rCBF}$ and $\mathrm{rCBV}$ within one to five days of treatment. ${ }^{4}$ Permeability of capillaries in the tumour has been shown to decrease both in experimental models, ${ }^{2}$ and in humans ${ }^{1}$ but although these changes may occur within the first 24 hours, MRI has failed to show significant changes in relaxation times that would indicate altered water content in either the tumour or the surrounding brain for up to six days after treatment with dexamethasone. ${ }^{7}$ Thus although capillary permeability may improve, there is not a significant change in the volume of oedema. More recently, Andersen et al analysed changes in the $\mathrm{T} 1$ (spin lattice or longitudinal relaxation time) in the zone of oedema around the tumour and found considerable heterogeneity. ${ }^{18}$ Although overall there was a change of only $2 \%$ in mean T1 after 24 hours of treatment with dexamethasone, the zone of oedema around the tumour that had the highest $\mathrm{T} 1$ values (termed regions of "superoedema") showed changes of up to $13 \% .{ }^{18}$ These authors have confirmed the slow time scale of oedema absorption with only a $12 \%$ change being seen in seven days. ${ }^{19}$ Again, they noted considerable heterogeneity, with the areas of "superoedema" showing changes of $50 \%$ over seven days. ${ }^{19}$

PROTON MAGNETIC RESONANCE SPECTROSCOPY Proton magnetic resonance spectroscopy ( ${ }^{1} \mathrm{H}-$ MRS) is being used increasingly often as a non-invasive method for analysing regional cerebral metabolism in vivo. Changes in ${ }^{1} \mathrm{H}-$ MRS have been shown in multiple sclerosis, epilepsy, cerebral infarction, AIDS, and brain tumours. ${ }^{20}$ The hope has been to develop a tumour specific metabolic profile to act as a fingerprint and aid in preoperative diagnosis. After, initially, a lack of reliable correlation, Preul et al have reported for certain tumours a $99 \%$ correlation between spectroscopic data and final pathological diagnosis. ${ }^{21}$ As a general rule in cerebral tumours, there is a decrease in the relative concentration of NAA and creatine/phosphocreatine together with an increase 
in choline and lactate. ${ }^{22}$ Despite the fact that dexamethasone is used routinely in these patients no previous study has analysed the changes in the spectra as a consequence of this drug.

Forty years after its identification by Tallan $e t$ $a l$, the role of NAA in cerebral metabolism remains uncertain. ${ }^{23}$ It is found only in the nervous system and is second only to glutamate in total concentration of free amino acids. ${ }^{24}$ In ${ }^{1} \mathrm{H}$-MRS, NAA produces a sharp spectral peak suggesting that it may be mobile and in free solution. ${ }^{24}$ Although regarded widely as a neuronal marker, there is still debate about its site of production. In particular, apparent increases in NAA seen during the recovery phase of various pathological states casts some doubt on this assumption. ${ }^{25-27}$ Some have suggested that NAA is involved in lipid synthesis in the production of myelin; $;^{24}$ or as a regulator of protein synthesis; or as a storage form of aspartate; or it is a breakdown product of another compound. ${ }^{24}$

In the present study we focused on changes in the zone around the tumour and found that the relative concentration of NAA apparently either decreased on the side of the oedema or increased on the contralateral side within 14 hours after treatment with dexamethasone. This implies that either the amount of NAA is changing, or there is a change in the relaxation behaviour of NAA. The degree of changes in relaxation time necessary to produce such large changes in apparent amounts of NAA present can be estimated by applying the standard spin echo signal equations with these pulse timing variables, and using previous estimates of NAA relaxation times ${ }^{2627} 29$ of 1650 $\mathrm{ms}$ (T1) and $330 \mathrm{~ms}$ (T2). Such calculations show that to account for the increased NAA signal in the contralateral region, either a $40 \%$ reduction in $\mathrm{T} 1$ or a $170 \%$ increase in $\mathrm{T} 2$ would be required. The apparent $14 \%$ reduction in oedematous NAA signal would require around a $30 \%$ increase in $\mathrm{T} 1$ or a $30 \%$ decrease in $\mathrm{T} 2$.

Such large T2 changes in oedematous NAA are not without precedent (although over the much longer time course of oedema resolution). Using two different TEs and two different TRs Kamada et al were able to estimate $\mathrm{T} 1$ and T2 for the oedematous NAA associated with brain tumours. ${ }^{26}{ }^{27}$ The T1 showed similar values to the NAA of normal brain but the $\mathrm{T} 2$ was found to have decreased by about $50 \% .{ }^{2627}$ The use of steroid treatment is not mentioned, but it is highly likely that all the patients had received treatment so their results would relate to our findings after treatment. In two patients who had long term follow up a gradual "normalisation of T2" occurred as the oedema resolved. ${ }^{26}{ }^{27}$ No changes in contralateral NAA were found.

Large changes in metabolite $\mathrm{T} 2$ values over a short time after initiation of treatment would therefore be required to explain these results. Changes in binding (and hence alterations in relaxation time) may indeed provide the explanation but it is also possible that we have detected increases in the transport out of a free and mobile molecule because of metabolic improvement. Other possibilities include increased utilisation (perhaps for lipid or protein synthesis for repair of damaged myelin) or increased breakdown (white matter having three times as much hydrolase activity as grey matter-despite only having half the concentration of NAA) ${ }^{24}$

If we are seeing real changes in NAA rather than relaxation effects, the apparent rise in NAA on the contralateral side is more difficult to explain but could represent either increased production or decreased utilisation or breakdown of this compound. McIntosh and Cooper have previously reported that drugs that normally raise cerebral concentrations of 5-hydroxytryptamine also increase concentrations of NAA. ${ }^{30}$

\section{CEREBRAL METABOLIC CHANGES AFTER}

DEXAMETHASONE

Corticosteroids cause systemic metabolic changes which include hyperglycaemia and catabolic effects that are usually mediated via intracellular receptors acting on gene expression. ${ }^{31}$ Likewise within the brain, steroids have been shown to act both genomically and nongenomically, ${ }^{31}$ in the second case via direct action on cell surfaces, alteration in ion permeability, and by the release of neurohormones and neurotransmitters. ${ }^{31}$ In the brain, two types of receptors bind glucocorticoids with high affinity: the type I mineralocorticoid receptor and the type II glucocorticoid receptors $^{32}$ and although the anatomical distribution of these receptors varies, studies have shown uptake in neurons and all classes of astrocytes (including oligodendrocytes). ${ }^{32}$ Studies using $\left[{ }^{3} \mathrm{H}\right]$ dexamethasone have shown uptake in the cerebral hemispheres of about $50 \%$ (with the remainder evenly divided between brainstem and cerebellum) in control animals and this increases to $75-80 \%$ after cerebral damage. ${ }^{33}$ Before trauma, $75 \%$ of the dexamethasone is located in astrocytes and $25 \%$ in neurons whereas after cerebral insult this changes to $48 \%$ bound to astrocytes and $42 \%$ to neurons. ${ }^{33}$ At the subcellular level, accumulation occurs in the microsomal, lysosomal, and cytoplasmic fractions of the damaged cells. ${ }^{33}$

Whatever the mechanism of action at the cellular level, steroids have been shown to preserve cerebral energy reserves. ${ }^{34}{ }^{36}$ In particular, in the neonatal period hydrocortisone has been shown to increase brain glucose, glycogen, B-hydroxybutarate, and ATP concentrations after decapitation in mice. ${ }^{35}{ }^{36}$ Recent studies using pretreatment with small doses of dexamethasone in a neonatal rat model of hypoxia-ischaemia have shown virtually complete protection. ${ }^{37}$ Even in adult models of ischaemia-in which no beneficial effect from treatment with steroids has been shown and there is even some evidence of a detrimental effect-prior treatment with dexamethasone has maintained ATP concentrations and electrical activity. ${ }^{34}$ Studies of tumour metabolism indicate a preference for non-oxidative metabolism with structural and kinetic changes in rate limiting enzymes and a reversion to fetal 
type enzymes. ${ }^{38}$ It may be, therefore, that dexamethasone acts by inducing changes in these enzymes, which in turn increase local energy reserves and improvement in cellular homeostasis.

\section{Conclusion}

The study confirms that there are significant early changes in cerebral metabolites after treatment with dexamethasone and that these changes can be monitored in vivo over the time that clinical benefit occurs. Our work also shows that the consequences of steroid administration must now be taken into account in the previous reports in which brain tumours were studied with MRS. Further studies are underway to examine changes in tissue energy status by using phosphorus MRS and to examine metabolite changes within the tumours.

The research reported in this paper was supported by the Scottish Hospitals Endowment Research Trust.

1 Jarden JO, Dhawan V, Poltorak A, et al. Positron emission tomographic measurement of blood-to-brain and bloodto-tumor transport of ${ }^{82} \mathrm{Rb}$ : the effect of dexamethasone and whole brain radiation therapy. Ann Neurol 1985;18: 636-46.

2 Shapiro WR, Hiesiger EM, Cooney GA, et al. Temporal effects of dexamethasone on blood-to-brain and bloodto-tumor transport of 14C-alpha-aminoisobutyric acid in to-tumor transport of $14 \mathrm{C}$-alpha-aminoisobut

3 Brooks D, Beaney $R$, Leenders K. The effect of dexamethasone therapy on cerebral haemodynamics, oxygen ethasone therapy on cerebral haemodynamics, oxygen
utilization and blood-brain barrier permeability in utilization and blood-brain barrier permeability in patients with brain tumours. In: Capildeo R, ed. Steroids in
diseases of the central nervous system. Chichester: John Wiley, 1989:59-68.

4 Leenders K, Beaney R, Brooks D, et al. Dexamethasone treatment of brain tumour patients: effects on regional cerebral blood flow, blood volume, and oxygen utilization. Neurology 1985;35:1610-6.

5 Reulen H, Hadjidimos H, Schurmann K. The effect of dexamethasone on water and electrolyte content and on $\mathrm{rCBF}$ in perifocal brain edema in man. In: Reulen $\mathrm{H}$, Schurmann $\mathrm{K}$, eds. Steroids and brain edema. Berlin: Springer-Verlag, 1972:239-52.

6 Sato O, Hara M, Asai T, et al. The effect of dexamethasone phosphate on the production rate of cerebrospinal fluid in the spinal subarachnoid space of dogs. $\mathcal{f}$ Neurosurg 1973;39:480-4.

7 Bell B, Kean D, Smith M, et al. Brain water measured by magnetic resonance imaging. Correlation with direct estimation and changes after mannitol and dexamethasone. Lancet 1987;i:66-8.

8 Ingraham F, Matson D, Mclaurin R. Cortisone and ACTH as an adjunct to the surgery of craniopharyngiomas. $N$ Engl ₹ Med 1952;246:568-71.

9 Galicich J, French L, Melby J. Use of dexamethasone in the treatment of cerebral edema associated with brain tumors. Lancet 1961;81:46-53.

10 Kirkham $S$. The palliation of cerebral tumours with highdose dexamethasone: a review. Palliat Med 1988;2:27-33.

11 Maxwell R, Long D, French L. The clinical effects of a synthetic gluco-corticoid used for brain edema in the practice of neurosurgery. In: Reulen $\mathrm{H}$, Schurmann $\mathrm{K}$, eds. tice of neurosurgery. In: Reulen $\mathrm{H}$, Schurmann $\mathrm{K}$, eds.
Steroids and brain edema. Berlin: Springer-Verlag, 1972: 219-32.

12 Alberti E, Hartmann A, Schutz H, et al. The effects of large doses of dexamethasone on the cerebrospinal fluid pressure in patients with supratentorial tumours. $\mathcal{F}$ Neuro 1978;217:173-181.

13 Brock M, Zillig C, Wiegand $\mathrm{H}$, et al. The influence of dexamethasone therapy in ICP in patients with tumours of the posterior fossa. In: Beks J, Bosch D, Brock M, eds. Intracranial pressure III. Berlin: Springer-Verlag, 1976 235-42.

14 Miller J, Leech P. The effect of mannitol and steroid therapy on intracranial volume-pressure relationships in patients. $f$ Neurosurg 1975;42:274-81

15 Johnston I, Gilday DC, Hendricks EB. Experimental effects of steroid withdrawal on cerebrospinal fluid absorption. F Neurosurg 1975;42:690-5.

16 Oppelt W, Patlak C, Rall D. Effects of certain drugs on cerebrospinal fluid production in the dog. Am $\mathcal{F}$ Physio 1964;206:247-50.

17 Martins A, Ramirez A, Solomon L, et al. The effect of dexamethasone on the rate of formation of cerebrospinal amethasone on the rate of formation of cereb

18 Andersen C, Haselgrove JC, Doenstrup S, et al. Resorption of peritumoural oedema in cerebral gliomas during dexamethasone treatment evaluated by NMR relaxatio time imaging. Acta Neurochir (Wein) 1993;122:218-24.

19 Andersen C, Astrup J, Gyldensted C. Quantitation of peritumoural oedema and the effect of steroids using NMRrelaxation time imaging and blood-brain barrier analysis. Acta Neurochir Suppl (Wien) 1994;60:413-5.

20 Duyn J, Gillen J, Sobering G, et al. Multisection proton MR spectroscopic imaging of the brain. Radiology 1993; 188:277-82.

21 Preul M, Caramanos Z, Villemure J, et al. Preoperative diagnosis of the five most common types of supratentorial brain tumors using in vivo biochemistry [abstract]. $f$ brain tumors using in

22 Henriksen $\mathrm{O}$, Wieslander $\mathrm{S}$, Gierris $\mathrm{F}$, et al. In vivo $1 \mathrm{H}$ spectroscopy of human intracranial tumors at 1.5 tesla. Preliminary experience at a clinical installation. Acta Radiol 1991;32:95-9.

23 Tallan $\mathrm{H}$, More S, Stein W. N-acetyl-L-aspartic acid in brain. F Biol Chem 1956;224:41-5.

24 Birken D, Oldendorf W. N-acetyl-L-aspartic acid: a literature review of a compound prominent in $1 \mathrm{H}-\mathrm{NMR}$ spec troscopic studies of brain. Neurosci Biobehav Rev 1989, 13:23-31.

25 Arnold DL. Reversible reduction of NAA after acute central nervous system damage. Proceedings of the Society of Magnetic Resonance in Medicine. 1992:643.

$26 \mathrm{Kamada} K$, Houkin $\mathrm{K}$, Iwasaki $\mathrm{Y}$, et al. In vivo proton magnetic resonance spectroscopy for metabolic changes of netic resonance spectroscopy for metabolic changes of
human brain edema. Neurol Med Chir (Tokyo) 1994; 34:676-81.

27 Kamada K, Houkin K, Hida K, et al. Localized proton spectroscopy of focal brain pathology in humans: significant effects of edema on spin-spin relaxation time. Magn Reson Med 1994;31:537-40.

28 D'Adamo A, Gidez L, Yatsu F. Acetyl transport mechanisms. Involvement of $\mathrm{N}$-acetyl aspartic acid in de novo fatty acid biosynthesis in the developing rat brain. Exp Brain Res 1968;5:267-73.

29 Frahm J, Bruhn H, Gyngell M. Localised proton NMR spectroscopy in different regions of the human brain in vivo. Relaxation time of cerebral metabolites. Magn Reson Med 1989;11:47-63.

30 McIntosh J, Cooper J. Function of $\mathrm{N}$-acetyl aspartic acid in the brain: effects of certain drugs. Nature 1964;203:658.

31 McEwen BS. Non-genomic and genomic effects of steroids on neural activity. TIPS Reviews 1991;12:141-7.

32 Vielkind U, Walencewicz A, Levine JM. Type II glucocorticoid receptors are expressed in oligodendrocytes and astrocytes. F Neurosci Res 1990;27:360-73.

33 Kostron H, Fischer J. Regional, cellular, and subcellular distribution of $[3 \mathrm{H}]$ dexamethasone in rat brain edema. Surg Neurol 1983;20:48-54.

34 Koide T, Wieloch TW, Siesjo BK. Chronic dexamethasone pretreatment aggravates ischemic neuronal necrosis. $\mathcal{f}$ Cereb Blood Flow Metab 1986;6:395-404.

35 Thurston $\mathrm{JH}$, Pierce RW. Increase of glucose and high energy phosphate reserve in the brain after hydrocortisone. F Neurochem 1969;16:107-11.

36 Thurston JH, Hauhart RE, Dirgo JA, et al. Mechanisms of increased brain glucose and glycogen after hydrocortiincreased brain glucose and glycogen after hydrocorti-
sone: possible clinical significance. Ann Neurol 1980;7: 515-23.

37 Chumas PD, Del Bigio MR, Drake JM, et al. A comparison of the protective effect of dexamethasone to other potential prophylactic agents in a neonatal rat model of cere bral hypoxia-ischemia. I Neurosurg 1993;79:414-20.

38 Whittle I. The biology of glioma. In: Miller J, Teasdale G, eds. Current Neurosurgery. New York: Churchill Livingstone, 1992:255-84. 